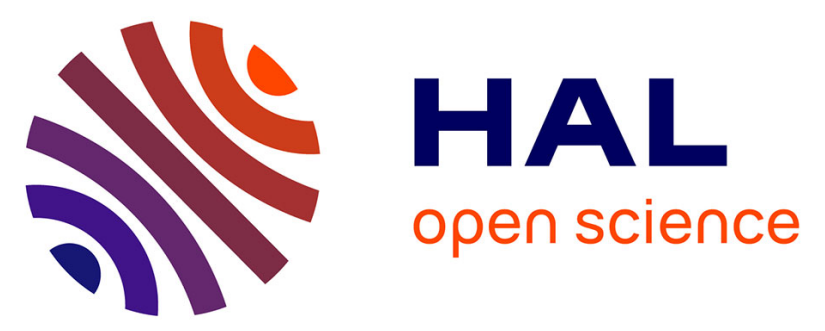

\title{
Loss of chemical bonds induced by high doses of $\gamma$-radiation in a PADC polymer film: The influence of dose and dose rate on radiation chemical yields
}

A.F. F Saad, Michel Fromm, Mona H Ibraheim, A.A. A El-Namrouty, Aya M Nwara, S.A. A Kandil, Mahmoud S Dawood

\section{To cite this version:}

A.F. F Saad, Michel Fromm, Mona H Ibraheim, A.A. A El-Namrouty, Aya M Nwara, et al.. Loss of chemical bonds induced by high doses of $\gamma$-radiation in a PADC polymer film: The influence of dose and dose rate on radiation chemical yields. Radiation Physics and Chemistry, 2021, 187, pp.109579. 10.1016/j.radphyschem.2021.109579 . hal-03557764

\author{
HAL Id: hal-03557764 \\ https://hal.science/hal-03557764
}

Submitted on 4 Feb 2022

HAL is a multi-disciplinary open access archive for the deposit and dissemination of scientific research documents, whether they are published or not. The documents may come from teaching and research institutions in France or abroad, or from public or private research centers.
L'archive ouverte pluridisciplinaire HAL, est destinée au dépôt et à la diffusion de documents scientifiques de niveau recherche, publiés ou non, émanant des établissements d'enseignement et de recherche français ou étrangers, des laboratoires publics ou privés. 


\section{Journal Pre-proof}

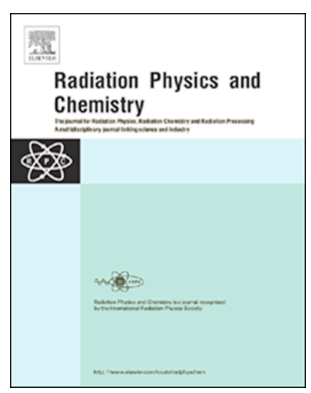

A.F. Saad, M. Fromm, Mona H. Ibraheim, A.A. El-Namrouty, Aya M. Nwara, S.A. Kandil, Mahmoud S. Dawood

PII:

S0969-806X(21)00229-2

DOI:

https://doi.org/10.1016/j.radphyschem.2021.109579

Reference: $\quad$ RPC 109579

To appear in: Radiation Physics and Chemistry

Received Date: 12 March 2021

Revised Date: 6 May 2021

Accepted Date: 16 May 2021

Please cite this article as: Saad, A.F., Fromm, M., Ibraheim, M.H., El-Namrouty, A.A., Nwara, A.M., Kandil, S.A., Dawood, M.S., Loss of chemical bonds induced by high doses of $y$-radiation in a PADC polymer film: the influence of dose and dose rate on radiation chemical yields, Radiation Physics and Chemistry, https://doi.org/10.1016/j.radphyschem.2021.109579.

This is a PDF file of an article that has undergone enhancements after acceptance, such as the addition of a cover page and metadata, and formatting for readability, but it is not yet the definitive version of record. This version will undergo additional copyediting, typesetting and review before it is published in its final form, but we are providing this version to give early visibility of the article. Please note that, during the production process, errors may be discovered which could affect the content, and all legal disclaimers that apply to the journal pertain.

(c) 2021 Elsevier Ltd. All rights reserved. 


\section{CRediT authorship contribution statement}

A.F. Saad: Conceptualization, Methodology, Writing - Reviewing, Editing. M. Fromm: Writing - Reviewing. S.A. Abd El Aal and Mona H. Ibraheim: Investigation. A.A. ElNamrouty Writing - Original draft preparation. Aya M. Nwara: Investigation, Data curate, Data analysis. S.A. Kandil: Investigation. Mahmoud S. Dawood: Writing - Original draft preparation, Investigation. 


\title{
Loss of chemical bonds induced by high doses of $\gamma$-radiation in a PADC polymer film: the influence of dose and dose rate on radiation chemical yields
}

\author{
A.F. Saad ${ }^{1,}$ M. Fromm ${ }^{2}$, Mona H. Ibraheim ${ }^{1}$, A.A. El-Namrouty ${ }^{1}$, Aya M. Nwara ${ }^{1}$, S.A. Kandil ${ }^{3}$, \\ Mahmoud S. Dawood ${ }^{1}$ \\ ${ }^{1}$ Physics Department, Faculty of Science, Zagazig University, Zagazig, Egypt \\ ${ }^{2}$ Laboratoire Chrono-environnement, UMR 6249, CNRS - Université de Franche-Comté. 16 route de \\ Gray. F-25030 Besançon cedex. France \\ ${ }^{3}$ Cyclotron Project, Nuclear Research Centre, Atomic Energy Authority, B.O. 13759, Egypt
}

\begin{abstract}
The effects of gamma rays on molecular properties of a poly allyl diglycol carbonate (PADC) polymer, commercially named as CR-39, have been studied. PADC films were exposed to gamma rays at doses ranging from 0.5 to $3 \mathrm{MGy}$. Gamma exposure induces considerable molecular modifications in PADC films. These modifications were analyzed using Fourier transform infrared (FT-IR) spectroscopy. FT-IR absorption spectra of the gamma irradiated samples show a change in the intensity and the shape of the absorption bands of the chemical groups forming the PADC polymer relative to the pristine one. We have determined G-values for the loss of carbonate ester and ether chemical moieties within PADC. By comparing our G-values with those from other studies, we show that dose rate and dose significantly affect the radiation chemical yields and play an important role of molecular bond kinematics.
\end{abstract}

Key Words: PADC; $\gamma$-ray; FT-IR; Molecular bonds; G-value, Dose; Dose rate

* Corresponding author. Tel.: +20 55 2303252; Fax: +20 55 2308213, Mobile: +20 1016746496;1225307497

E-mail address: abdallahsaad56@hotmail.com, afsaad@zu.edu.eg(A.F. Saad). 


\section{Introduction}

Since the end of the seventies of the last century, poly allyl diglycol carbonate (PADC) polymer material, CR-39, is used for radiation detection (Cartwright et al., 1978; Cassou and Benton, 1978). PADC is commonly used in various branches of science and technology such as nuclear and particle physics, cosmic rays, neutron dosimetry and radiation biology [Nikezic and Yu, 2004; Price, 2005]. Exposure to ionizing radiation such as gamma and X-rays, alpha particles and heavy ions can play a prominent role in modifying physical, chemical, molecular, structural, optical, electrical and thermal properties of the polymeric materials (Marletta, 1990; Steckenreiter et al., 1997; Saha et al., 2000; Saad et al., 2005; Khan et al., 2005; Singh and Prasher, 2006; Sharma et al., 2007; Kumar et al., 2011; Raghuvanshi et al., 2012; Saad et al., 2014a,b). In general, chain scission of PADC polymer is seen as the major process of the degradation of the main chain of that polymer. Such scission process caused by ionizing radiation (UV radiation, X-rays, gamma rays, swift ions), is known to release carbon mono oxide and carbon dioxide (Yamauchi et al., 2003; Saad et al., 2005) and references therein.

In order to describe molecular and chemical damages formed in PADC and other particle track detector (PTD) polymers by ionizing radiations; an international collaboration that aimed at studying radiation damage using spectroscopic measurements has been set up between Japan and France (T. Yamauchi, T. Kusumoto, R. Barillon, and their co-workers) (Barillon and Yamauchi, 2003; Yamauchi et al., 2005a,; Yamauchi et al., 2008a,b; Mori et al., 2009; Yamauchi, 2012; Mori et al., 2011; Mori et al., 2013; Barillon et al., 2013; Kusumoto et al., 2015; Kusumoto et al., 2016; Yamauchi et al., 2018). This team was able to highlight which are the chemical units of the PADC structure that are involved in the destructive process at the origin of ionizing radiation damage trails as mentioned in a recent review paper (Fromm et al., 2019). That vast study is based on analyses of spectroscopic 
experimental data of the loss/appearance of specific chemical functions further to PADC/PTD polymer exposure to various ionizing radiations such as alpha particles, gamma rays and heavy ions. The main achievements of these studies are connected with a quantitative determination of the sensibility of PADC chemical functional groups to ionizing radiations expressed in terms of cross-sections and G-values (radiation chemical yields) for the loss of given chemical groups. As previously mentioned, it was also shown by other groups and further confirmed, that carbon dioxide formation goes together with radiation damage (Rickards et al., 1992; Chong et al., 1997; Saad et al., 2001; Yamauchi et al., 2001; Malek, 2002; Yamauchi et al., 2005b; Saad et al., 2005). In addition, it has also been established that the amount of $\mathrm{CO}_{2}$ in the detector is closely related not only to the latent track formation mechanism but also to the track detection sensitivity (Saad et al., 2001). Carbon dioxide absorbed in the polymer material plays indeed a positive role in the detector's sensitization (Fujii et al., 1995; Csige, 1997; Fujii et al., 1997; Baradacs et al., 2008; d'Errico et al., 2017).

O’Sullivan et al. (O'Sullivan et al., 1981) measured G value of $\gamma$ - ray (an average of 1.25 MeV from ${ }^{60} \mathrm{Co}$ ) scissions in PADC per $100 \mathrm{eV}$ as $\approx 10$, from the correlation between the minimum value of the primary ionization rate and the $G$ values for various types of polymers based on the observed bulk etching rates. Mori et al., 2009 studied the effect of $\gamma$ ray irradiation on the radiation chemical yield, for loss of carbonate ester bonds in PADC films by means of FT-IR spectrometry. They found that the G value is 20 (scissions $/ 100 \mathrm{eV}$ ) and is somewhat higher than that from heavy ion irradiations (147 MeV Fe ions) (Yamauchi et al., 2008a; Mori et al., 2011). These authors also evaluated the chemical radiation yield for other kinds of heavy ions and protons to different functional groups in PADC films, for example, ether and ethylene. They also found that the highest $\mathrm{G}$ values were observed in PADC films irradiated by protons, namely about 20 scissions $/ 100 \mathrm{eV}$ for both bonds, namely 
ether and carbonate ester. The values decreased down to about 5 scissions/100 eV for films irradiated with heavier ions. Studying gamma irradiation of PADC at higher doses can be an effective way to understand the latent track formation, because the local dose in a heavy ion track core exceeds several MGys in heavy ions. Recently it was also shown that a critical dose of $~ 50-60 \mathrm{kGy}$ exists above which carbonate ester density in PADC start decreasing (Kusumoto, et al., 2020). For ether bonds, such threshold was not observed.

In the current paper, we propose to study the changes of the molecular structure induced by $\gamma$-radiation at different high doses over the range 0.5 to $3 \mathrm{MGy}$. For this purpose, FT-IR spectrometer as a standard technique of spectroscopic analysis of polymeric materials is used.

\section{Experimental procedure}

Fig. 1 shows the chemical structure of a poly allyl diglycol carbonate (PADC) high polymer which has a length of chain between two adjacent carbonate groups in symmetrical positions. PADC sheets of TASTRAK used in this investigation were manufactured by Track Analysis Systems Ltd. (TASL), Bristol, UK. Polymeric detector samples of a uniform thickness of $750 \mu \mathrm{m}$ were cut to a size of $2 \times 3 \mathrm{~cm}^{2}$. The detector samples were irradiated in atmosphere at room temperature using a commercial gamma irradiator of type MC-20 (Russia) with ${ }^{60} \mathrm{Co}$ energy source which provides a dose rate of $1.2 \mathrm{kGy} / \mathrm{h}$. The PADC samples were irradiated with different doses ranging from 0.5 to $3 \mathrm{MGy}$ of gamma rays. The samples were irradiated for various times in order to get variable doses. These irradiations were performed at the Gamma Cell, Nuclear Research Centre, Inshas , Atomic Energy Authority .Egypt. The FT-IR spectrometer was operated in attenuated total reflection (ATR) mode. The working range of the spectrometer is $4600-400 \mathrm{~cm}^{-1}$. A resolution of $4 \mathrm{~cm}^{-1}$, scan numbers of 
16 and apodization of cosine were used. The Fourier transform infrared (FT-IR) spectrometer model of Vertex 70, made in Germany is used. FT-IR spectroscopy was performed in the wave number range $4000-400 \mathrm{~cm}^{-1}$ at room temperature on the pristine and irradiated CR-39 samples.

\section{Results}

\subsection{FT-IR spectral changes due to $\gamma$-ray irradiation}

FT-IR spectra in ATR mode for pristine and irradiated samples of PADC films are shown in Fig. 2. It is easy to find a significant difference in FT-IR spectra between irradiated and unirradiated samples of PADC because changes in the molecular structure due to our irradiation conditions were high, thus it can be easily detected in ATR mode. Absorption bands were identified. The broad absorption peak around $2920 \mathrm{~cm}^{-1}$ is due to $\mathrm{C}-\mathrm{H}$ stretching. Two strong absorption peaks at 1734 and $1240 \mathrm{~cm}^{-1}$ are assigned to $\mathrm{C}=\mathrm{O}$ and $\mathrm{C}-\mathrm{O}-\mathrm{C}$ bonds, respectively, which compose carbonate ester bonds (Gagnadre et al., 1993; Darraud et al., 1994; Lounis-Mokrani wt al., 2003; Saad et al., 2001). Three weak absorption peaks at 1132, 1076 and $1022 \mathrm{~cm}^{-1}$ are assigned to ether bonds. In addition, an absorption peak at $959 \mathrm{~cm}^{-1}$ is assigned to wagging vibration of the double bond $\mathrm{C}=\mathrm{C}$. Two other absorption peaks at 878 and $785 \mathrm{~cm}^{-1}$ are assigned to $\mathrm{C}-\mathrm{H}$ rocking out-of-plane deformation (Gagnadre et al., 1993; Lounis-Mokrani wt al., 2003). Indeed, the $\mathrm{OH}$ groups at around $3500 \mathrm{~cm}^{-1}$ are clearly suppressed in FT-IR spectra in ATR mode for the pristine and exposed samples of PADC as shown in Fig. 2. This is due to that the yield of $\mathrm{OH}$ group formation is below the detection limit in that mode compared to the case of another transmission mode, as presented in our previous studies (Saad et al., 2001; Saad et al., 2005). 
A new broad band (as a shoulder) at wave number $1627 \mathrm{~cm}^{-1}$, which could be identified as $\mathrm{C}=\mathrm{C}$ bond, is found in the FT-IR spectra of gamma exposed samples of PADC films as also shown in Fig. 2. It can be seen that these shoulder absorption bands are strongly affected by gamma irradiation in their shapes and/or intensities. The band area of $\mathrm{C}=\mathrm{C}$ at $1627 \mathrm{~cm}^{-1}$ is plotted as a function of irradiation dose, as shown in Fig. 3. The net area of the $\mathrm{C}=\mathrm{C}$ absorption band, which actually represents the net absorbance, $\Delta \mathrm{A}$, is given by $\mathrm{Eq}$.

$$
\Delta \mathrm{A}=\mathrm{A}_{\text {irr }}-\mathrm{A}_{\mathrm{o}}
$$

where $\mathrm{A}_{\mathrm{irr}}$ and $\mathrm{A}_{\mathrm{o}}$ are the area under the absorption peak of the irradiated and unirradiated PADC samples, respectively. The band area of $\mathrm{C}=\mathrm{C}$ is quickly enhanced with increasing dose up to $1 \mathrm{MGy}$, then it somewhat decreases with higher dose at 1.5 MGy. Beyond 1.5 MGy the net absorbance sharply increases up to a maximum at 2.5 MGy, and then sharply decreased at 3 MGy as can be seen in Fig. 3. In fact, the response of PADC film to the gamma dose of 2.5 MGy reveals a differing behavior. This inconsistent response to that dose was also observed by other standard analysis techniques as reported in our recent study (Saad et al., 2018). In general, the PADC film might have undergone a very considerable degree of scission of its chain groups, generating a new broad band of $\mathrm{C}=\mathrm{C}$ at $1627 \mathrm{~cm}^{-1}$, as a result of the $\gamma$-ray exposure particularly for that dose. This will be the subject of a separate study. The band assignments for most important chemical functional groups in a PADC polymer were given in the literature and are enlisted in Table 1.

The relative changes in the bonds IR absorption intensities have been evaluated from the relative increase or decrease in the intensity of the peak associated to the functional groups present in the PADC high polymer. IR absorption bands as obtained from the pristine and the irradiated samples of PADC polymer for different doses ranging from 0.5 to $3 \mathrm{MGy}$. It is apparent that the absorption bands observed at 1734, 1400, 1240, 1132, 1076, 1022, 959, 878 and $785 \mathrm{~cm}^{-1}$ decrease in height due the $\gamma$-ray exposure. It is clear that the absorbance 
decreases after irradiation for all the peaks except for the triplet bands at 2960, 2925 and $2853 \mathrm{~cm}^{-1}$ which show an opposite trend. However, there is a little shift in the peak positions of some absorption bands after irradiation with high doses of $\gamma$-rays. In the next paragraphs, we will pay attention to the two strong bands of the carbonate ester bond and the three weak absorption peaks of the ether bond.

\subsection{Loss of chemical bonds in a PADC film}

\subsubsection{Loss of carbonate ester bonds}

The normalized absorbance, $\mathrm{A} / \mathrm{A}_{0}$, was attained for each examined absorbed dose, where $\mathrm{A}$ is the absorbance of the band considered after exposure and $\mathrm{A}_{0}$ is that of the pristine one. The normalized absorbance is equal to the survival fraction, $\mathrm{N} / \mathrm{N}_{0}$, which is the ratio of the number density of the considering chemical bond, $\mathrm{N}$, to that of pristine, $\mathrm{N}_{0}$. That is, $\mathrm{A} / \mathrm{A}_{0}$ $=\mathrm{N} / \mathrm{N}_{0}$. Fig. 4 shows the changes in the normalized absorbance, $\mathrm{A} / \mathrm{A}_{0}$, of the two peaks for carbonate ester bonds as a function of $\gamma$-ray dose over the range 1.5 to $3 \mathrm{MGy}$ (just to focusing on the higher doses). Each peak reduced in height monotonically in the examined regions of dose. This figure shows the results for both $\mathrm{C}=\mathrm{O}$ and $\mathrm{C}-\mathrm{O}-\mathrm{C}$ bonds, presenting a clear linear decline of the normalized absorbance against the absorbed dose for both bonds up to $3 \mathrm{MGy}$. Trends for the two peaks that compose the carbonate ester bond are almost similar. We used the following simple formula (Mori et al., 2009):

$\mathrm{N} / \mathrm{N}_{0}=1-\mathrm{k}_{\mathrm{i}} \cdot \mathrm{D}$

where $\mathrm{D}$ is the absorbed dose in a unit of Gy and $\mathrm{k}_{\mathrm{i}}$ is an experimental constant for the bond $\mathrm{i}$ in $\mathrm{Gy}^{-1}$. The constant $\mathrm{k}_{\mathrm{i}}$ corresponds to the slope of the fitting lines in Fig. 4. Normalized absorbances are converted to $\mathrm{G}$ values for the loss of $\mathrm{C}=\mathrm{O}$ and $\mathrm{C}-\mathrm{O}-\mathrm{C}$ bonds per $100 \mathrm{eV}$, using the following simple relation (Mori et al., 2009): 
$\mathrm{G}=9.64 \times 10^{6} \mathrm{~N}_{0} \mathrm{k}_{\mathrm{i}}$

where $\mathrm{N}_{0}$ is in $\mathrm{mol} / \mathrm{kg}$. $\mathrm{N}_{0}$ is $7.30 \mathrm{~mol} / \mathrm{kg}$ for the carbonate ester bond in PADC. The calculations give $\mathrm{G}$ values of 4.7 and 6.3 for $\mathrm{C}=\mathrm{O}$ and $\mathrm{C}-\mathrm{O}-\mathrm{C}$ bonds, respectively. Finally, the average result, $\mathrm{G}$ value for the loss of carbonate ester bonds in PADC is determined to be about 5.5 as tabulated and listed in Table 2.

In the current study, the $G$ value for gamma ray is considerably lower than that obtained in a previous study (Mori et al., 2009). With PADC as a target and ${ }^{60} \mathrm{Co}$ as a gamma source in both studies; the dose rate used by Mori et al. was $4.5 \mathrm{kGy} / \mathrm{h}(1.25 \mathrm{~Gy} / \mathrm{s})$ and we used $1.2 \mathrm{kGy} / \mathrm{h}(0.33 \mathrm{~Gy} / \mathrm{s})$, in atmospheric conditions within dose range 0.5 to $3 \mathrm{MGy}$. An important decrease of the G-value from 20 (Mori et al., (Mori et al., 2009) to about 6 (this work) in conjunction with a decrease of the dose rate (by a factor 3.75) is observed. The decrease of dose rate lowers thus radiation chemical yields for destruction of $\mathrm{C}=\mathrm{O}$ and $\mathrm{C}-\mathrm{O}-$ $\mathrm{C}$ bonds. The so-called dose rate effects (DRE) in polymer properties under irradiation in an oxygen environment are known to be very significant and connected with chain reactions of oxidizing radiation destruction initiated by radiolysis species of radical type (Briskman et al., 2004). DRE yields either from physical or chemical aspects. At high dose rates diffusion limited oxidation (DLO) effects become evident cause for dose rate effect and at low dose rates more complex chemical reactions determine the magnitude of dose rate effect (Sipilä, 2016). Generally, high dose rates of ionizing radiation (typically > $100 \mathrm{kGy} / \mathrm{h}$ ) have less impact on the properties of polymers compared to lower dose rates (this work $1-5 \mathrm{kGy} / \mathrm{h}$ ). It was for example shown that at equal total doses the carbonyls and hydroperoxide yields in LDPE (Low density polyethylene) are greatly enhanced when decreasing the dose rate from 0.69 to $0.04 \mathrm{kGy} / \mathrm{h}$ (Buttafava et al., 2007). Herein, dose rates (namely $4.5 \mathrm{kGy} / \mathrm{h}$ and 1.2 $\mathrm{kGy} / \mathrm{h}$ ) belong to the low or intermediate dose rates. DRE and thus oxidizing radiation destruction generally follows three steps in polymers, namely: a free radical reacts with 
molecular oxygen to generate peroxy radicals which themselves abstract hydrogen, then the formed peroxide decomposes to create carbonyl functions. It is clear from Fig.2 that no carbonyl function is created, therefore conventional DRE in an oxygen environment may not be invoked here as a major pathway. Moreover, a recent study of the radiation degradation of Poly (ethylene-co-vinyl acetate) (EVA), containing a carbonyl moiety, demonstrated that the DRE is negligible in the range $0.4-1.5 \mathrm{kGy} / \mathrm{h}$ (Fabiani et al., 2015). Additionally, it may be quite unlikely to invoke the commercial origin of the polymers used as the cause of observed variations of G-values. Baryotrack ${ }^{\mathrm{TM}}$ used by Mori et al. and Tastrak ${ }^{\mathrm{TM}}$ (this work) are both PADCs, thus with identical structures but with small differences in their initiator compositions $(<5 \%)$.

Coming back to the dose rates and especially to low or intermediate dose rates, it has been shown that in the case of aliphatic compounds; when irradiation is carried out at low dose rates in air, the effects are strongly dependent on the dose rate (Wilski, 1990). It is indeed generally assumed that the rate of radicals generation is proportional to the dose rate (Sarcinelli et al., 1997), hence with a dose rate ratio of 3.75 between Mori et al. experiments and the present study it is quite probable that the lower G-value we obtained ( 8 instead of 20 for Mori et al.) is a clear manifestation of dose rate dependence.

\subsubsection{Loss of ether bonds}

Fig. 5 shows the changes in the normalized absorbance, $A / A_{0}$, for ether bonds as a function of the $\gamma$-ray dose. The first two peaks of ether group (peaks number: 6 and 7) at 1132 and $1076 \mathrm{~cm}^{-1}$ have more or less the same trend on the $\gamma$-ray dose up to $3 \mathrm{MGy}$, showing almost a linear decrease that can be expressed by Eq. (2). Beyond 2 MGy, the absorbance of the first peak at $1132 \mathrm{~cm}^{-1}$ completely disappear up to $3 \mathrm{MGy}$, while the absorbance of the second peak at $1076 \mathrm{~cm}^{-1}$ (peak number: 7) is still observed till the end of the dose range as clearly seen in Fig 2. The third peak of that group at $1022 \mathrm{~cm}^{-1}$ (peak number: 8 ) behaves 
differently when compared to the two other peaks. It is difficult to assess the absorbance for that peak. So, we assess the constant $k_{i}$ for the ether bonds from peaks with wave numbers 1132 to $1076 \mathrm{~cm}^{-1}$ (peaks number: 6 and 7). Eq. (3) gives G-values for the loss of ether bonds to be 7.3 and 6.2 at absorption bands of 1132 and $1076 \mathrm{~cm}^{-1}$, respectively. The average G value for the loss of the ether bonds in PADC is determined to be about 6.9 (scission/100 eV) as seen in Table 2. Based on the loss measurements for both carbonate ester and ether bonds, it is found that the rate of reduction in the normalized absorbance of ether bonds is barely higher than that of carbonate ester bonds. On the other hand, the peak No. 6 (one of ether groups at $1132 \mathrm{~cm}^{-1}$ ) has completely disappeared after 2 MGy. This means that it has suffered complete radiation destruction, so its G-value cannot be determined at the higher doses used.

As noticed above, the molecular bonds of ether functions in the PADC polymer have suffered a serious degradation due to $\gamma$-irradiation, at different high doses over the range 0.5 to $3 \mathrm{MGy}$. Overall, the radiation molecular yield, $\mathrm{G}$ value, has a dependence on the gamma dose in PADC. At high doses over the range 0.5 to $3 \mathrm{MGy}$, the yield for the loss of ether bonds is barely higher than that of carbonate ester bonds, confirming that the ether part being generally considered more radio-sensitive than the carbonate ester one (Mori et al., 2011; Mori et al., 2013). Here again, the G-value we obtain is smaller than the one measured by Mori et al., 2013. G-values obtained herein both for ether and carbonate ester function loss are relatively close together (average values of respectively 6.9 and 5.5) as those obtained by Mori et al. are quasi the triple (typically 20 for both chemical functions) (Mori et al., 2011; Mori et al., 2013; Kusumoto et al., 2016). So, we may argue that such difference militates in favor of a dose rate effect. We can observe that when the dose rate of ${ }^{60} \mathrm{Co}$ gamma rays decreases by a factor 3.75 , exposing PADC sheets in air leads to a reduction of radiation chemical yields of a factor $3-3.6$ for ether and carbonate ester function loss. 


\section{Discussion and conclusion}

Molecular modification due to $\gamma$-ray damage in the PADC film has been examined by means of FT-IR spectrometry, which was exposed to $\gamma$-radiation at incident energies 1.25 $\mathrm{MeV}$ with different doses ranging from 0.5 to $3 \mathrm{MGy}$. The radiation molecular yield, i.e., $\mathrm{G}$ values, have been determined to be 5.5 (scission per $100 \mathrm{eV}$ ) for the loss of the carbonate ester bonds in PADC film exposed to gamma ray. Similar analyses have been performed for the ether bonds at the same doses. The G-value for the loss of these bonds was about 6.9. In this study, dose and dose rate dependence was observed, for both ether and carbonate ester function loss. It is quite interesting to note that the dose rate effect observed corresponds to a reduction of the dose of 3.75 in comparison with the study of others (Mori et al., 2009) and that this reduction yields a decrease of experimentally determined G-values by typically 3 3.6 folds.

The results presented herein demonstrate for the first time the existence of a dose rate effect in PADC exposed to Co-60 $\gamma$-radiation. If this last remark does not constitute in itself a major advance (dose rate effects in polymers are well-known); it indicates whatever that dose rate may be an interesting tool to be used in further studies. In spite of Co-60 gamma ray dose is clearly affects the G-values, variations of dose rates could also be an interesting way to adjust G-values in order to simulate heavy-ion irradiation effects using gamma rays. Actually, the radiation chemical yield for the loss of carbonate ester bonds obtained in the present study is close to those measured by Yamauchi et al., 2008 for $147 \mathrm{MeV}$ Fe ions. The used gamma rays (Co-60) are characterized by an electronic LET of $0.4 \mathrm{keV} / \mu \mathrm{m}$ as the Fe ions we have 
$5200 \mathrm{keV} / \mu \mathrm{m}$. The G-value we measured for the loss of ether moiety is close to the one measured for $46 \mathrm{MeV}$ Ar ions (LET = $3880 \mathrm{keV} / \mu \mathrm{m}$ ) (Yamauchi et al., 2008).

\section{References}

Baradacs, E., Csige, I., \& Rajta, I. (2008). CO2 treatment and vacuum effects in proton beam micromachining of PADC. Radiation measurements, 43(8), 1354-1356.

Barillon, R., \& Yamauchi, T. (2003). Chemical bond scission induced by ${ }^{1} \mathrm{H}^{+},{ }^{16} \mathrm{O}^{8+}$, and $\gamma$ rays in a cellulose nitrate detector (O-082). Nuclear Instruments and Methods in Physics Research Section B: Beam Interactions with Materials and Atoms, 208, 336-339.

Barillon, R., Mori, Y., Kanasaki, M., Yamauchi, T., \& Yasuda, N. (2013). Chemical cross sections induced by ions in solid organic detectors: Experimentation and simulation. Radiation measurements, 50, 38-42.

Briskman, B. A., Klinshpont, E. R., \& Stepanov, V. F. (2004). Dose Rate Effects in Polymer Materials Irradiated in Vacuum. In Protection of Materials and Structures from Space Environment (pp. 99-111). Springer, Dordrecht.

Buttafava, A., Tavares, A., Arimondi, M., Zaopo, A., Nesti, S., Dondi, D., ... \& Faucitano, A. (2007). Dose rate effects on the radiation induced oxidation of polyethylene. Nuclear Instruments and Methods in Physics Research Section B: Beam Interactions with Materials and Atoms, 265(1), 221-226.

Cartwright, B. G., Shirk, E. K., \& Price, P. B. (1978). A nuclear-track-recording polymer of unique sensitivity and resolution. Nuclear Instruments and Methods, 153(2-3), 457-460.

Cassou, R. M., \& Benton, E. V. (1978). Properties and applications of CR-39 polymeric nuclear track detector. Nuclear Track Detection, 2(3), 173-179.

Chong, C. S., Ishak, I., Mahat, R. H., \& Amin, Y. M. (1997). UV-VIS and FTIR spectral studies of CR-39 plastics irradiated with X-rays. Radiation measurements, 28(1-6), 119122. 
Csige, I. (1997). Post-irradiation sensitization of CR-39 track detector in carbon dioxide atmosphere. Radiation measurements, 28(1-6), 171-176.

Darraud, C., Bennamane, B., Gagnadre, C., Decossas, J. L., \& Vareille, J. C. (1994). Optical modifications of polymers by ion beam irradiation. Polymer, 35(11), 2447-2451.

d'Errico, F., de Vasconcelos, D. A., Ciolini, R., \& Hulber, E. (2017). Track size distributions in CR-39 neutron dosimeters treated with carbon dioxide. Radiation Measurements, 106, 607-611.

Fabiani D., Linde E., Gedde U. W. (2015). Inverse effect in simultaneous thermal and radiation aging of EVA insulation. eXPRESS Polymer Letters,9(4), 384-393.

Fromm, M., Kodaira, S., Kusumoto, T., Barillon, R., \& Yamauchi, T. (2019). Role of intermediate species in the formation of ion tracks in PADC: a review. Polymer Degradation and Stability, 161, 213-224.

Fujii, M., Yokota, R., Kobayashi, T., \& Hasegawa, H. (1995). Sensitization of polymeric track detectors with carbon dioxide. Radiation measurements, 25(1-4), 141-144.

Fujii, M., Yokota, R., Kobayashi, T., \& Hasegawa, H. (1997). Effect of vacuum, oxygen and carbon dioxide on the track registration in SR-90 and CR-39. Radiation measurements, 28(1-6), 61-64..

Gagnadre, C., Decossas, J. L., \& Vareille, J. C. (1993). IR spectroscopy studies of polycarbonate irradiated by $\mathrm{H}+$ and $\mathrm{Li}+$ ions. Nuclear Instruments and Methods in Physics Research. Section B, 73(1), 48-52.

Khan, E. U., Malik, F., Qureshi, I. E., Husaini, S. N., Ali, N., \& Mehmood, A. (2005). Measurement of neutron fluence with CR-39 using a UV spectrophotometer. Radiation measurements, 40(2-6), 583-586.

Kumar, V., Sonkawade, R. G., Chakarvarti, S. K., Kulriya, P., Kant, K., Singh, N. L., \& Dhaliwal, A. S. (2011). Study of optical, structural and chemical properties of neutron irradiated PADC film. Vacuum, 86(3), 275-279.

Kusumoto, T., Mori, Y., Kanasaki, M., Ueno, T., Kameda, Y., Oda, K., ... \& Yamauchi, T. (2015). Yields on the formation of $\mathrm{OH}$ groups and the loss of $\mathrm{CH}$ groups along nuclear tracks in PADC films. Radiation Measurements, 83, 59-62. 
Kusumoto, T., Mori, Y., Kanasaki, M., Ikenaga, R., Oda, K., Kodaira, S., ... \& Yamauchi, T. (2016). Radiation chemical yields for the losses of typical functional groups in PADC films for high energy protons registered as unetchable tracks. Radiation Measurements, 87, 35-42.

Kusumoto, T., Okada, S., Kurashige, H., Kobayashi, K., Fromm, M., Raffy, Q., Ludwig, N., Kanasaki, M., Oda, K., Honda, Y., Tojo, S., Groetz, J.E., Ogawara, R., Kodaira, S., Barillon, R., Yamauchi T. (2020) Evidence for a critical dose above which damage to carbonate ester bonds in PADC appear after gamma ray and ultra-soft X-ray exposures. Radiation Physics and Chemistry 170, 108628

Lounis-Mokrani, Z., Fromm, M., Barillon, R., Chambaudet, A., \& Allab, M. (2003). Characterization of chemical and optical modifications induced by $22.5 \mathrm{MeV}$ proton beams in CR-39 detectors. Radiation measurements, 36(1-6), 615-620.

Malek, M. A., \& Chong, C. S. (2002). Generation of CO2 in $\gamma$-ray-irradiated CR-39 plastic. Radiation measurements, 35(2), 109-112.

Marletta, G. (1990). Chemical reactions and physical property modifications induced by keV ion beams in polymers. Nuclear Instruments and Methods in Physics Research Section B: Beam Interactions with Materials and Atoms, 46(1-4), 295-305.

Mori, Y., Ikeda, T., Yamauchi, T., Sakamoto, A., Chikada, H., Honda, Y., Oda, K. (2009). Radiation chemical yield for loss of carbonate ester bonds in PADC films exposed to gamma ray. Radiation measurements, 44(2), 211-213.

Mori, Y., Yamauchi, T., Kanasaki, M., Hattori, A., Oda, K., Kodaira, S., Barillon, R. (2013). Vacuum effects on the radiation chemical yields in PADC films exposed to gamma rays and heavy ions. Radiation measurements, 50, 97-102.

Mori, Y., Yamauchi, T., Kanasaki, M., Maeda, Y., Oda, K., Kodaira, S., Barillon, R. (2011). Radiation chemical yields for loss of ether and carbonate ester bonds in PADC films exposed to proton and heavy ion beams. Radiation measurements, 46(10), 1147-1153.

Nikezic, D., \& Yu, K. N. (2004). Formation and growth of tracks in nuclear track materials. Materials Science and Engineering: R: Reports, 46(3-5), 51-123.

O'Sullivan, D., Price, P. B., Kinoshita, K., \& Willson, C. G. (1981). Correlative studies of track-etch behaviour and chemical development of lithographic polymer resists. Nuclear Tracks, 5(4), 344-345. 
Price, P. B. (2005). Science and technology with nuclear tracks in solids. Radiation Measurements, 40(2-6), 146-159..

Raghuvanshi, S. K., Ahmad, B., Srivastava, A. K., Krishna, J. B. M., \& Wahab, M. A. (2012). Effect of gamma irradiation on the optical properties of UHMWPE (Ultra-highmolecular-weight-polyethylene) polymer. Nuclear Instruments and Methods in Physics Research Section B: Beam Interactions with Materials and Atoms, 271, 44-47.

Rickards, J., Zironi, E. P., \& Andrade, E. (1992). Gas ejection from CR-39 under ion bombardment. Radiation effects and defects in solids, 124(4), 383-390.

Saad, A. F., Atwa, S. T., Yasuda, N., \& Fujii, M. (2001). FT-IR spectroscopy of carbon dioxide in CR-39 and SR-90 track detectors irradiated with ions and gamma-rays at different energies and fluences. Radiation measurements, 34(1-6), 51-54.

Saad, A. F., Atwa, S. T., Yokota, R., \& Fujii, M. (2005). Radiation-induced modifications on spectroscopic and thermal properties of CR-39 and SR-90 nuclear track detectors. Radiation measurements, 40(2-6), 780-784.

Saad, A. F., Al-Faitory, N. M., \& Mohamed, R. A. (2014)a. Study of the optical properties of etched alpha tracks in annealed and non-annealed CR-39 polymeric detectors. Radiation Physics and Chemistry, 97, 188-197.

Saad, A. F., Saad, N., \& Abdalla, Y. K. (2014)b. Changes in the thermal properties of PADC film-based nuclear track detectors produced by high doses of $\gamma$-radiation. Nuclear Instruments and Methods in Physics Research Section B: Beam Interactions with Materials and Atoms, 325, 79-83.

Saad, A. F., Ibraheim, M. H., Nwara, A. M., \& Kandil, S. A. (2018). Modifications in the optical and thermal properties of a CR-39 polymeric detector induced by high doses of $\gamma$ radiation. Radiation Physics and Chemistry, 145, 122-129.

Saha, A., Chakraborty, V., \& Chintalapudi, S. N. (2000). Chemical modification of polypropylene induced by high energy carbon ions. Nuclear Instruments and Methods in Physics Research Section B: Beam Interactions with Materials and Atoms, 168(2), 245251.

Sarcinelli, L., Valenza, A., \& Spadaro, G. (1997). Inverse response of polypropylene to gamma radiation under vacuum. Polymer, 38(10), 2307-2313. 
Sharma, T., Aggarwal, S., Kumar, S., Mittal, V., Kalsi, P. C., \& Manchanda, V. K. (2007). Effect of gamma irradiation on the optical properties of CR-39 polymer. Journal of materials science, 42(4), 1127-1130.

Singh, S., \& Prasher, S. (2006). A comparison of modifications induced by $\mathrm{Li}^{3+}$ and $\mathrm{O}^{6+}$ ion beam to Makrofol-KG and CR-39 polymeric track detectors. Nuclear Instruments and Methods in Physics Research Section B: Beam Interactions with Materials and Atoms, 244(1), 252-256.

Sipilä, K. (2016). Methods used in evaluating severity of dose rate effect on low dose rates. VTT Technical Research Centre of Finland. VTT Research Report VTT-R-04773-16

Steckenreiter, T., Balanzat, E., Fuess, H., \& Trautmann, C. (1997). Chemical modifications of PET induced by swift heavy ions. Nuclear Instruments and Methods in Physics Research Section B: Beam Interactions with Materials and Atoms, 131(1-4), 159-166..

Wilski, H. (1990). Radiation stability of polymers. International Journal of Radiation Applications and Instrumentation. Part C. Radiation Physics and Chemistry, 35(1-3), 186-189.

Yamauchi, T., Takada, S., Ichijo, H., \& Oda, K. (2001). Raman and near-IR study on proton irradiated CR-39 detector and the effect of air-leak on damage formation. Radiation measurements, 34(1-6), 69-73.

Yamauchi, T., Nakai, H., Somaki, Y., \& Oda, K. (2003). Formation of $\mathrm{CO}_{2}$ gas and $\mathrm{OH}$ groups in CR-39 plastics due to gamma-ray and ions irradiation. Radiation measurements, 36(1-6), 99-103.

Yamauchi, T., Yasuda, N., Asuka, T., Izumi, K., Masutani, T., Oda, K., \& Barillon, R. (2005)a. Track core size estimation for heavy ions in CR-39 by AFM and UV methods. Nuclear Instruments and Methods in Physics Research Section B: Beam Interactions with Materials and Atoms, 236(1-4), 318-322.

Yamauchi, T., Barillon, R., Balanzat, E., Asuka, T., Izumi, K., Masutani, T., \& Oda, K. (2005)b. Yields of $\mathrm{CO}_{2}$ formation and scissions at ether bonds along nuclear tracks in CR-39. Radiation measurements, 40(2-6), 224-228.

Yamauchi, T., Watanabe, S., Seto, A., Oda, K., Yasuda, N., \& Barillon, R. (2008)a. Loss of carbonate ester bonds along $\mathrm{Fe}$ ion tracks in thin CR-39 films. Radiation measurements, 43, S106-S110. 
Yamauchi, T., Mori, Y., Oda, K., Yasuda, N., Kitamura, H., \& Barillon, R. (2008)b. Structural modification along heavy ion tracks in poly (allyl diglycol carbonate) films. Japanese Journal of Applied Physics, 47(5R), 3606.

Yamauchi, T., Mori, Y., Morimoto, A., Kanasaki, M., Oda, K., Kodaira, S., ... \& Barillon, R. (2012). Thresholds of Etchable Track Formation and Chemical Damage Parameters in Poly (ethylene terephthalate), Bisphenol A polycarbonate, and Poly (allyl diglycol carbonate) Films at the Stopping Powers Ranging from 10 to 12,000 keV/ $\mu \mathrm{m}$. Japanese Journal of Applied Physics, 51(5R), 056301.

Yamauchi, T., Kusumoto, T., Ueno, T., Mori, Y., Kanasaki, M., Oda, K., ... \& Barillon, R. (2018). Distinct step-like changes in $\mathrm{G}$ values for the losses of typical functional groups in poly (ethylene terephthalate) along boron ion tracks around the detection threshold. Radiation Measurements, 116, 51-54. 
Table 1

Assignments of FTIR bands of functional groups in PADC polymer film.

\begin{tabular}{|c|c|c|c|}
\hline $\begin{array}{l}\text { Peak } \\
\text { Number }\end{array}$ & $\begin{array}{l}\text { Band } \\
\text { position } \\
\left(\mathrm{cm}^{-1}\right)\end{array}$ & Functional Groups & Reference \\
\hline 1 & 2926 & $\begin{array}{l}\text { Symmetric } \mathrm{CH}_{2} \text { stretching vibration } \\
\text { of aliphatic hydrocarbons }\end{array}$ & $\begin{array}{l}\text { (Gagnadre et al., 1993; Saad et al., } \\
\text { 2001; Yamauchi et al., 2001) }\end{array}$ \\
\hline 2 & 1734 & $\begin{array}{l}\text { Ester } \mathrm{C}=\mathrm{O} \text { stretching vibration of the } \\
\text { alkyl carbonate }-\mathrm{C}-\mathrm{CO}-\mathrm{C}\end{array}$ & $\begin{array}{l}\text { (Gagnadre et al., 1993; Saad et al., } \\
\text { 2001; Yamauchi et al., 2001) }\end{array}$ \\
\hline $2 *$ & 1627 & $\begin{array}{l}\text { Hydrocarbon } \mathrm{C}=\mathrm{C} \text { stretching of the } \\
\text { vinyl group } \\
-\mathrm{CH}=\mathrm{CH}_{2}\end{array}$ & Present work \\
\hline 3 & 1452 & $\begin{array}{l}\mathrm{CH}_{2} \text { deformation vibration and } \\
\mathrm{OCH}_{2} \text { wagging vibration of }-\mathrm{CO}-\mathrm{O}- \\
\mathrm{CH}_{2}\end{array}$ & nis-Mokrani et al., 2003) \\
\hline 4 & 1400 & $\begin{array}{l}\text { In-plane }-\mathrm{CH}_{2}-\text { bending vibration } \\
\text { of }-\mathrm{CO}-\mathrm{O}-\mathrm{CH}_{2}\end{array}$ & (Lounis-Mokrani et al., 2003) \\
\hline 5 & 1240 & $\begin{array}{l}\text { Asymmetric stretching vibration of } \\
\mathrm{C}-\mathrm{O}-\mathrm{C} \text { of aliphatic ester }\end{array}$ & (Yamauchi et al., 2001) \\
\hline 6 & 1132 & $\begin{array}{l}\text { Symmetric stretching vibration of the } \\
\mathrm{C}-\mathrm{O}-\mathrm{C} \text { group of the saturated } \\
\text { aliphatic ether }\end{array}$ & $\begin{array}{c}\text { (Gagnadre et al., 1993; Darraud et } \\
\text { al., 1994; Lounis-Mokrani et al., } \\
\text { 2003) }\end{array}$ \\
\hline 7 & 1076 & $\begin{array}{l}\text { Asymmetric stretching vibration of } \\
\text { the } \mathrm{C}-\mathrm{O}-\mathrm{C} \text { group of the saturated } \\
\text { aliphatic ether }\end{array}$ & $\begin{array}{l}\text { (Darraud et al., 1994; Lounis- } \\
\text { Mokrani et al., 2003) }\end{array}$ \\
\hline 8 & 1022 & $\begin{array}{l}\text { Symmetric stretching vibration of the } \\
\mathrm{C}-\mathrm{O}-\mathrm{C} \text { group of the saturated } \\
\text { aliphatic ether }\end{array}$ & $\begin{array}{l}\text { (Darraud et al., 1994; Lounis- } \\
\text { Mokrani et al., 2003) }\end{array}$ \\
\hline 9 & 959 & $\begin{array}{l}\text { Wagging vibration of the double } \\
\text { bond } C=C\end{array}$ & $\begin{array}{l}\text { (Lounis-Mokrani et al., } \\
\text { 2003) }\end{array}$ \\
\hline 10 & 878 & $\begin{array}{l}\mathrm{C}-\mathrm{H} \text { rocking out-of-plane } \\
\text { deformation }\end{array}$ & $\begin{array}{l}\text { (Lounis-Mokrani et al., } \\
\text { 2003) }\end{array}$ \\
\hline 11 & 785 & $\begin{array}{l}\text { Ether group or } \mathrm{C}-\mathrm{H} \text { rocking out-of- } \\
\text { plane deformation }\end{array}$ & (Saad et al., 2001) \\
\hline
\end{tabular}




\section{Table 2}

Radiation chemical yields for loss of carbonate ester and ether bonds in a PADC polymer film.

Bonds $\gamma$ - radiation

$\begin{array}{ll}\text { G-value } & \text { Average } \\ \text { G-value }\end{array}$

$\begin{array}{lclll}\text { Carbonate ester } & \mathrm{C}-\mathrm{O}-\mathrm{C} & 1240 \mathrm{~cm}^{-1} & 6.3 & 5.5 \approx 6 \\ & \mathrm{C}=\mathrm{O} & 1734 \mathrm{~cm}^{-1} & 4.7 & \\ & & & & \\ \text { Ether } & \mathrm{C}-\mathrm{O}-\mathrm{C} & 1132 \mathrm{~cm}^{-1} & 7.5 & 6.9 \approx 7\end{array}$




$$
\begin{aligned}
& \mathrm{CH}_{2}-\mathrm{CH}_{2}-\mathrm{O}-\stackrel{\mathrm{O}}{\mathrm{C}}-\mathrm{O}-\mathrm{CH}_{2}-\mathrm{CH}=\mathrm{CH}_{2} \\
& \stackrel{1}{\mathrm{O}} \\
& \underset{\mathrm{CH}}{\mathrm{C}}-\mathrm{CH}_{2}-\mathrm{O}-\underset{\mathrm{O}}{\mathrm{C}}-\mathrm{O}-\mathrm{CH}_{2}-\mathrm{CH}=\mathrm{CH}_{2}
\end{aligned}
$$

Fig. 1. 


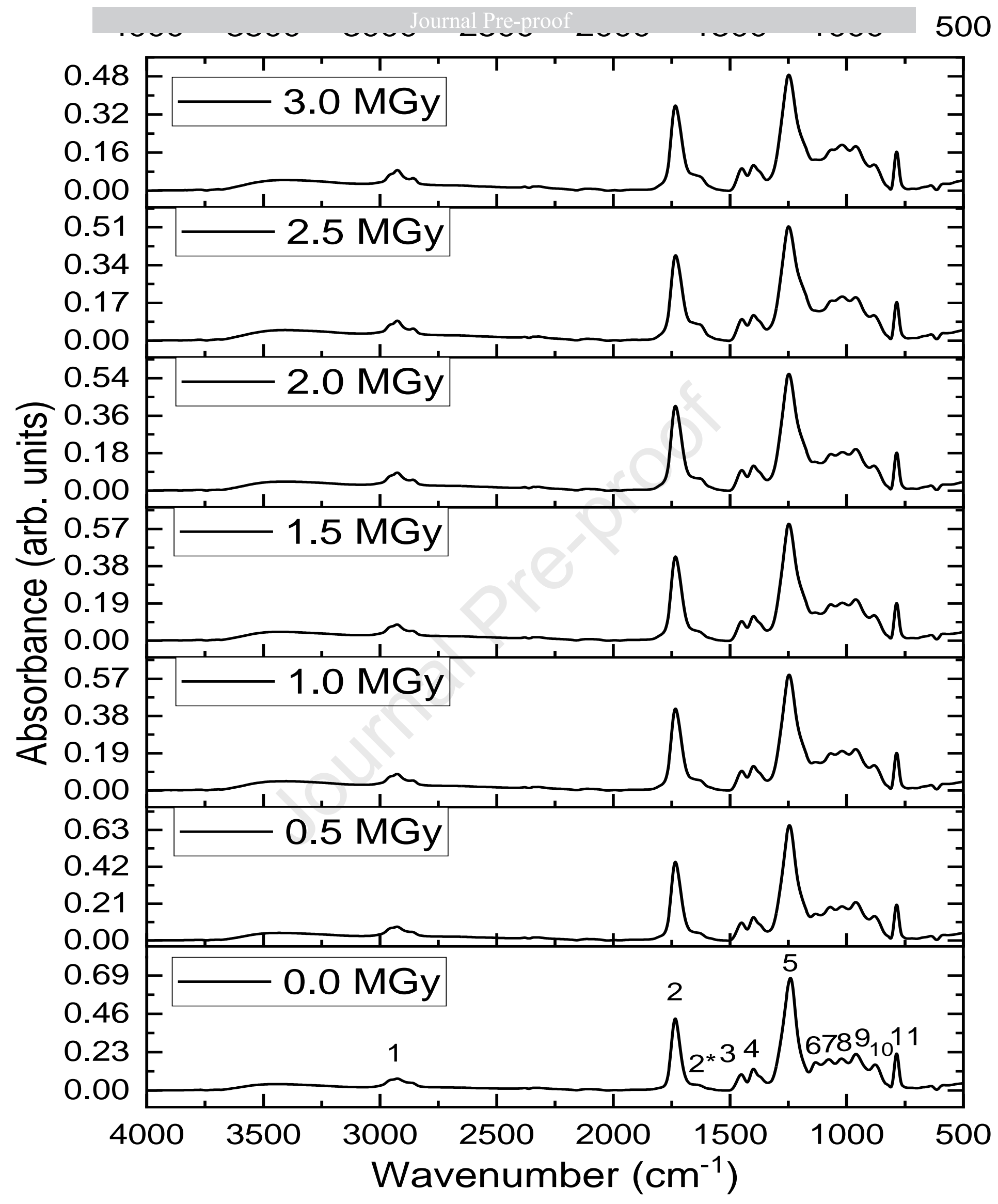

Fig. 2 


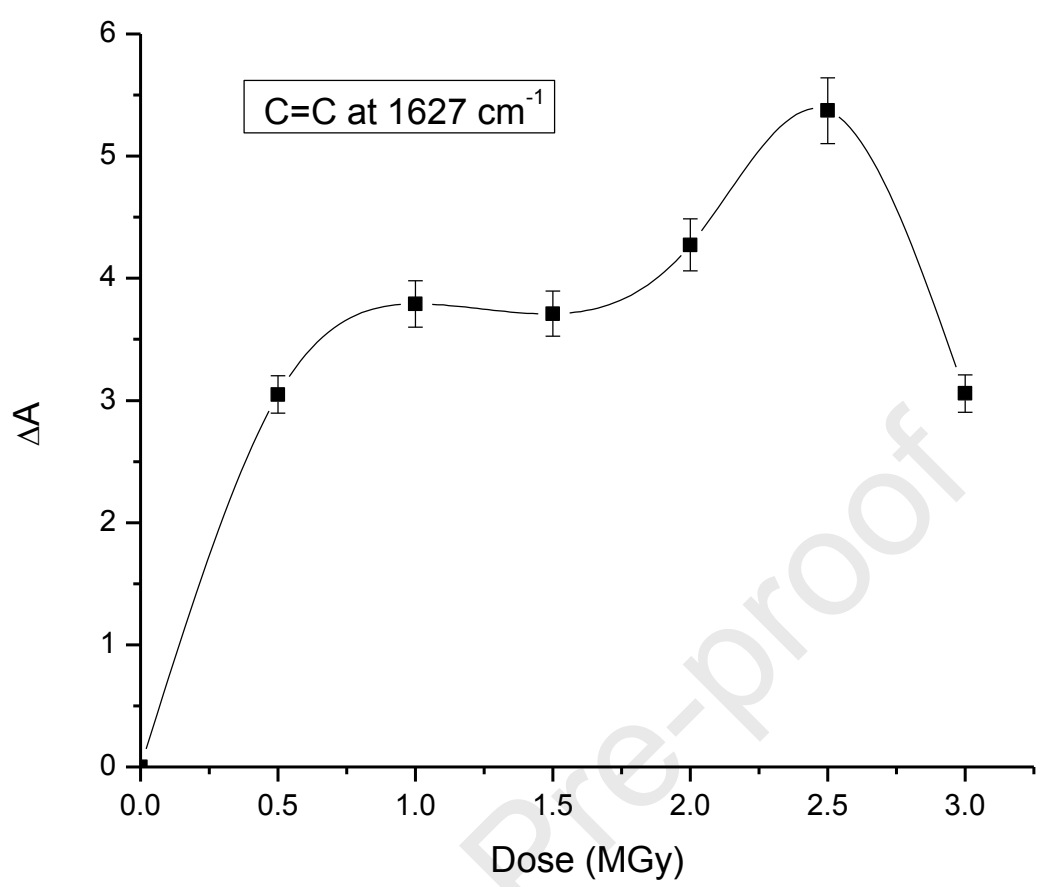

Fig. 3 


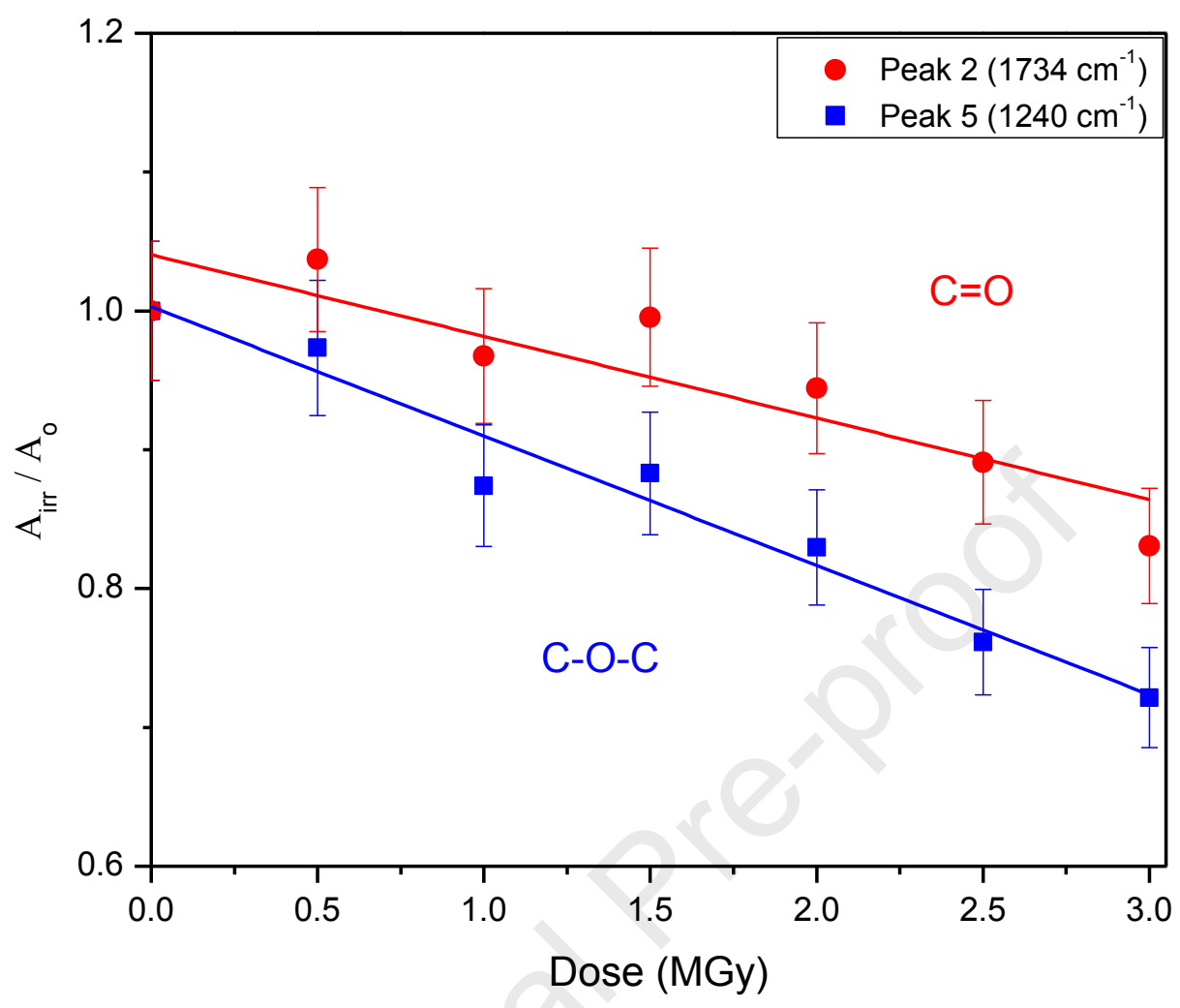

Fig. 4 
Fig. 5.
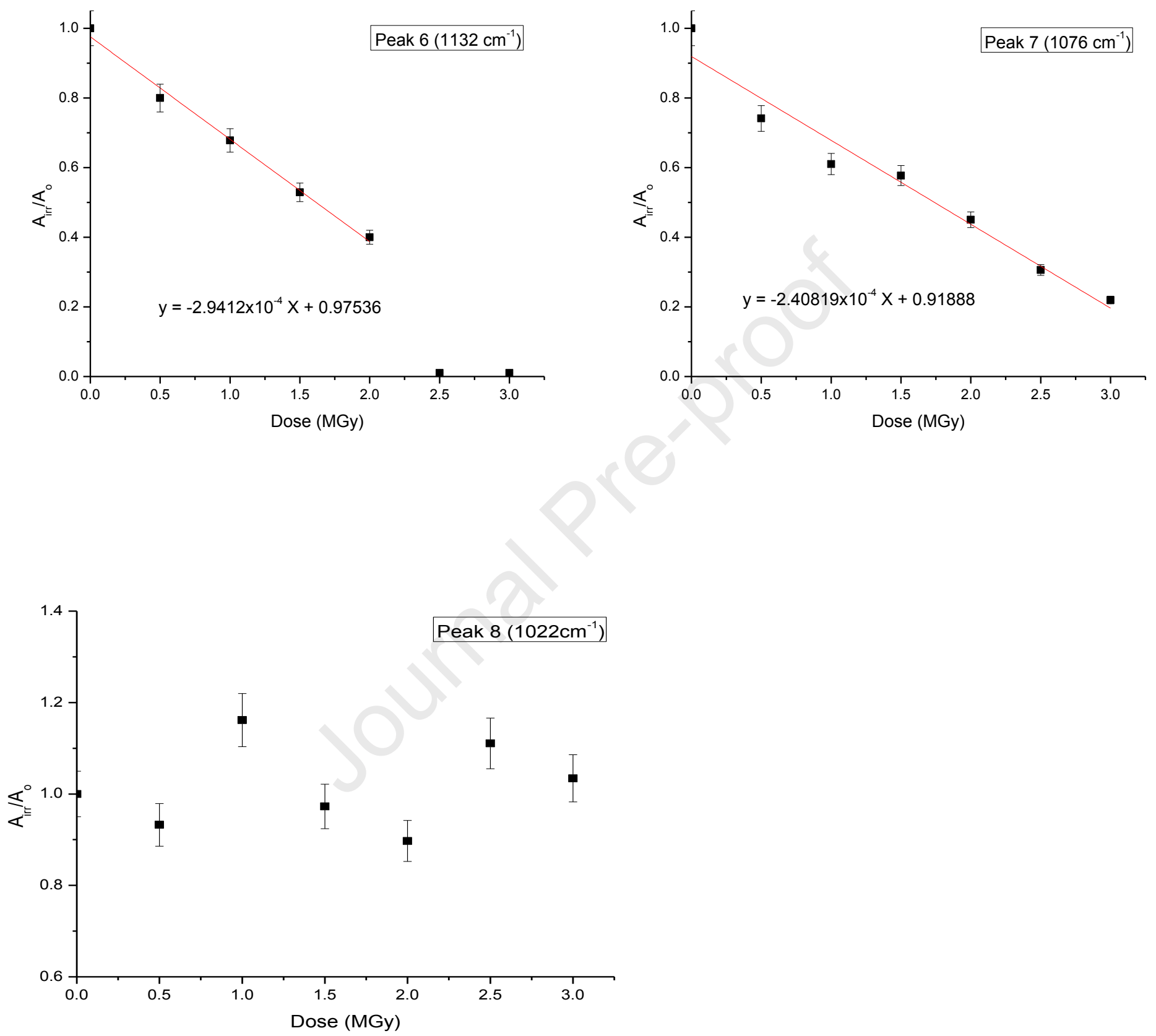


\section{Highlights}

- Gamma irradiation has been proposed to study PADC polymer film.

- Molecular properties of pristine and irradiated PADC detectors were investigated.

- Radiation chemical yields, G values, for loss of bonds in PADC have been assessed.

- G values for the loss of carbonate ester and ether bonds are 5.5 and 6.9, respect.

- Radiation chemical yields are influenced by dose and dose rate of gamma rays. 


\title{
Conflict of Interest Forms
}

\author{
No conflict
}




\section{]]][-Declaration of interests}

$\bigotimes$ The authors declare that they have no known competing financial interests or personal relationships that could have appeared to influence the work reported in this paper.

$\square$ The authors declare the following financial interests/personal relationships which may be considered as potential competing interests:

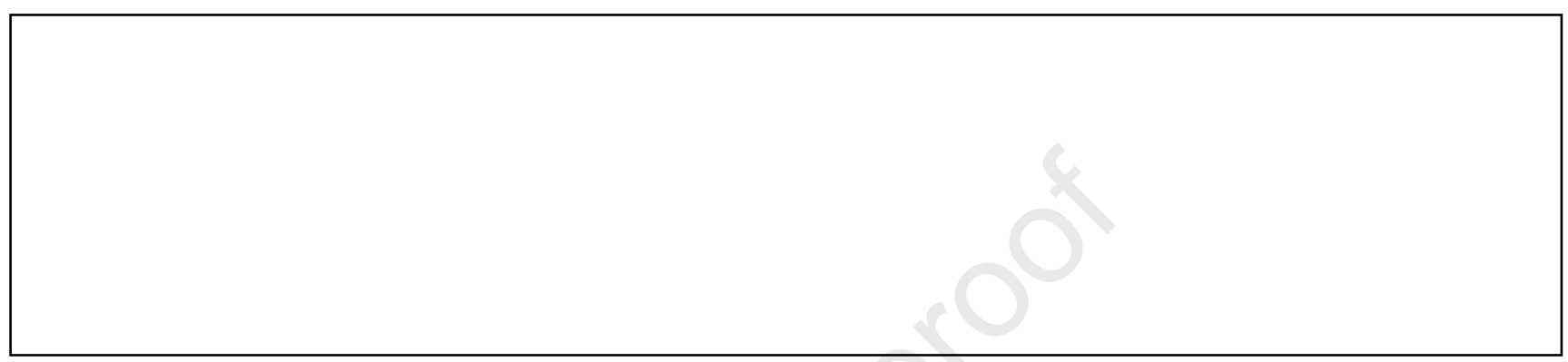

